\title{
Experimental Comparative Study of potential anxiolytic effect of Vitamin $C$ and Buspirone in rats
}

\author{
Ghada Farouk Soliman, Aida Khattab, and Mariam Habil
}

Department of Pharmacology, Faculty of Medicine, Cairo University, Cairo, Egypt

Corresponding author: Ghada Farouk Soliman, MD, Department of Pharmacology, Faculty of Medicine, Cairo University, Cairo, Egypt

Submission Date: May 17, 2017; Acceptance date: February 25 ${ }^{\text {th }}$, 2018; Publication date: February $28^{\text {th }}, 2018$

Citation: Soliman G.F., Khattab A., Habil M., Experimental Comparative Study of potential anxiolytic effect of Vitamin $\mathrm{C}$ and Buspirone in rats. Functional Foods in Health and Disease 2018; 8(2): 91-106. https://doi.org/10.31989/ffhd.v8i2.365

\begin{abstract}
Background: Anxiety disorders are the most common of all mental health problems. They are more prevalent among women than among men, and they affect children as well as adults. The aim of the current study is to evaluate this problem via an experimental animal model and try to explore its possible mechanisms by studying the effect of Vitamin $\mathrm{C}$ compared to Buspirone on anxiety in rats induced by Monosodium Glutamate (MSG).
\end{abstract}

Materials and Methods: 56 healthy adult male albino rats (Sprague-Dawley) weighing 200-250 gm were used and divided into 7 groups (8 rats each). The first and the second groups were provided with normal saline and MSG at a dose of $2 \mathrm{mg} / \mathrm{g}$ p.o. respectively. The other five groups were given MSG and treated daily in the following ways: The third and fourth groups were treated with Vitamin C (100, $200 \mathrm{mg} / \mathrm{kg}$ p.o) respectively. The fifth group was treated with only Buspirone (10 mg/kg p.o.), while the sixth and seventh groups were given a combination of Buspirone and Vitamin C with $(100,200 \mathrm{mg} / \mathrm{kg}$ ) respectively. After 3 weeks, the open field and successive alleys tests were used to assess behavioral changes. The percentage change of systolic blood pressure (SBP) was measured. Additionally, glutathione reductase (GR), malondialdehyde (MDA), and corticosterone levels were determined biochemically.

Results: The results after 3 weeks revealed that the MSG group showed significant anxiogenic effects in both behavioral tests, with an increased percentage change of SBP in addition to increased malondialdehyde and corticosterone levels measured statistically. While the results of the treated groups revealed that the Vitamin C $(100 \mathrm{mg} / \mathrm{kg})$ treated group demonstrated significant improvement in anxiety levels in the open field test, there were no significant changes in the biochemical assessment. However, the vitamin C $(200 \mathrm{mg} / \mathrm{kg})$ treated group revealed a significant anxiolytic effect in behavioral tests, improved glutathione and malondialdehyde with low corticosterone level. Administration of buspirone revealed significant anxiolytic effects, which is lower than that of vitamin C $(200 \mathrm{mg} / \mathrm{kg})$. However, it caused significant increase in the 
oxidative stress and corticosterone levels. A combination of buspirone with Vitamin C $(200 \mathrm{mg} / \mathrm{kg})$ only demonstrated significant anxiolytic effect in both tests and a significant decrease of corticosterone.

Conclusion: MSG has neurotoxic effect leading to anxiogenic behaviors in rats which are opposed by Vitamin C. Furthermore, as an antioxidant, vitamin C protects against the oxidative stress induced by MSG. Moreover, it lowers the high corticosterone level associated with MSG or buspirone administration.

Keywords: MSG, vitamin C, buspirone, glutathione reductase, malondialdehyde, open field, successive alleys

\section{INTRODUCTION}

Anxiety disorders are a growing health problem all over the world and, like many psychiatric disorders, they have different aetiologies [1]. These disorders include Oxidative Stress (OS), which is the shift in balance between oxidant/antioxidant in favor of oxidants. This occur due to either increased levels of reactive oxygen species, or the importance of the antioxidant system [2]. Among the harmful effects of ROS, lipid peroxidation is the most important as it leads to the breakdown of lipids with formation of a wide variety of products such as malondialdehyde (MDA) and hydrocarbons (e.g. ethane and ethylene [3]). The brain, with its high oxygen consumption and lipid-rich environment, is highly susceptible to oxidative stress or redox imbalances, which may explain why oxidative stress is implicated in several mental disorders including depression, anxiety disorders, schizophrenia, and bipolar disorder [4] .

Chronic stress or prolonged exposure to glucocorticoids can lead to hippocampal atrophy by producing dendritic retraction. This may play an important role in the pathogenesis of a range of neuropsychiatric disorders, including anxiety disorders such as post-traumatic stress disorder (PTSD) [5, 6].

Another possible mechanism is the disturbance of serotonin (5-HT) levels, as its depletion in medial prefrontal cortex is associated with increased anxiety-like behavior in rats [7]. This is evident in the tendency to develop new obsessions [8]. Monosodium Glutamate (MSG) is one of the flavor enhancers used in modern nutrition which can cause anxiety-like behavior in rats [9] through the increasing production of oxygen free radicals. Additionally, it was reported that anxiety leads to more liability to develop hypertension [10].

Vitamin $\mathrm{C}$ is one of many antioxidants which are able to reduce ROS, resulting in the formation of a relatively stable ascorbate free radical (AFR). The AFR is reduced back to ascorbate within cells by NADH and NADPH-dependent reductases [11]. Accordingly, it can block damage caused by oxygen free radicals, which appears to be one of the roles in the pathophysiology of anxiety [12]. Consequently, several researchers have investigated its anxiolytic effect. Furthermore, it helps regeneration of tetrahydrobiopterin (BH4), which acts as a cofactor in conversion of tryptophan into 5-HT [13]. It is able to reduce cardiovascular adrenergic drive in hypertensive patients, and therefore may help to decrease hypertension associated with anxiety [14].

Buspirone is $5-\mathrm{HT}_{1 \mathrm{~A}}$ receptor partial agonist that is approved to be useful in generalized anxiety disorders [15].

The present work was performed to evaluate the protective effect of Vitamin $\mathrm{C}$ compared to Buspirone and in combination against anxiety induced by monosodium glutamate in albino rats. 


\section{MATERIALS AND METHODS}

Animals: About 56 healthy adult male albino rats Sprague-Dawley weighing 200-250 gm were used. Rats were bred in the animal house at Kasr El-Aini, Faculty of medicine, Cairo University and divided into 7 groups. Each group of rats was housed in a cage at ordinary room temperature, humidity, natural daily light dark cycle, and fed with the standard diet in the form of rodents' pellets and clean water. The rats were left for an initial adaptation period for at least one week before subjecting them to the experimental manipulation(s). All the experiments were carried out between 9.00 a.m. and 2.00 p.m. and were conducted according to the regulations of the committee of bioethics for animal experiments of Kasr Al-Aini.

Drugs: Vitamin C (L-Ascorbic acid) and Monosodium glutamate were obtained from the International Company for Scientific and Medical Supplies in Mazallat, Cairo, Egypt as a powder and Buspar as tablets, with each tablet containing $15 \mathrm{mg}$ of Buspirone hydrochloride which were manufactured by Smithkline Beecham (SB) Egypt for Glaxo Smith Kline (GSK). Tablets were crushed and then dissolved in distilled water. All of the drugs were used orally using a gastric gavage needle.

Kits: Corticosterone ELISA Kit produced by Assay pro LLC., USA, Glutathione reductase Kit produced by the Bio-Diagnostic Company, Egypt, to detect its level in plasma by Ultra Violet method and Lipid Peroxide Kit produced by the Bio-Diagnostic Company, Egypt, to detect its level in plasma using the Colorimetric method.

Experimental design: After acclimatization for 1 week, the rats were divided into 7 groups (8 rats each) and subjected to the study for 3 weeks: The first and the second groups were provided with normal saline and Monosodium glutamate (MSG) at a dose of (2 mg/g p.o.) [9] respectively. The other five groups were given MSG and treated in the following ways: The third and fourth groups were treated with Vitamin C (100 mg/kg p.o.) [10] and (200 mg/kg p.o.) [11] respectively. The fifth group was treated daily with Buspirone (10 mg/kg p.o.) only [12], while the sixth and seventh groups were treated with a combination of Buspirone and Vitamin $\mathrm{C}$; the sixth group with $100 \mathrm{mg} / \mathrm{kg}$ and the seventh with $200 \mathrm{mg} / \mathrm{kg}$.

\section{7 groups (each 8 adult rats)}

Treated for 3 weeks

All of these groups received oral MSG 2 mg/g
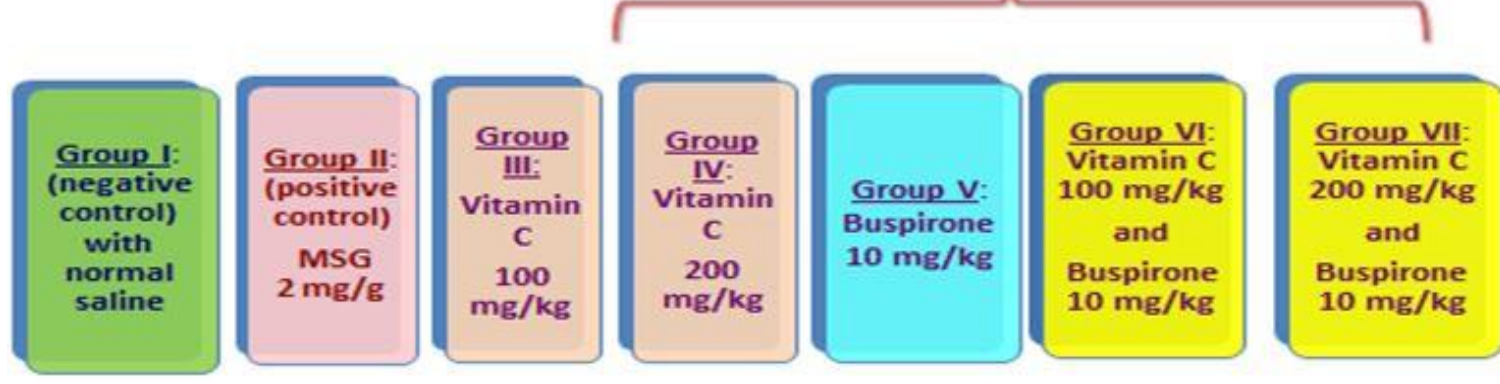

Figure 1: Diagram showing the different groups with different drugs administrated 
Estimation of anxiety pharmacologically

Open field test according to [13]: The open field test (OFT) analyzed many parameters that include total distance moved (ambulation score), time spent along the walls (thigmotaxis) compared to the time in center, rearing (standing on rear limbs), and levels of defecation and urination. The test duration was 5 minutes [14]. At the beginning of the test, each rat was placed individually at the center of the square area. The ambulation score (number of square crossed) and rearing number (standing upright on the hind legs) were calculated. After each individual test session, the floor was cleaned with $70 \%$ ethanol [15].

Successive alleys test according to [16]: The apparatus was elevated approximately $50 \mathrm{~cm}$ by clamping the back-extended floor of alley 1 to a laboratory bench. Each rat was placed in section 1 of the apparatus away from sections 2-4. The behavior was recorded for 3 minutes using a Sony digital camera (Model DSCW380S). The amount of time spent in each alley was calculated. More time in alley (1) reflected higher anxiety [17].

Blood pressure measurement [18]: The systolic blood pressure (SBP) of each rat was measured before and after the behavioral tests [19]. SBP was determined using non-invasive blood pressure methodology in conscious rats. For each rat, SBP values were calculated as the mean of a minimum of three measurements. Then the percentage change in SBP after behavioral tests was calculated: Percentage change of SBP (in $\mathrm{mmHg})=(\mathrm{SBP}$ after tests $-\mathrm{SBP}$ before tests) / SBP before tests x 100 .

Biochemical estimation: Blood samples were collected using citrate as anticoagulant. Then, samples were centrifuged at 3,000 rpm for 10 minutes at $+4^{\circ} \mathrm{C}$. The yellow plasma samples were collected with a pipette without disturbing the white buffy layer: Plasma Glutathione reductase (GR) activity [20]. GR catalyzes the reduction of oxidized glutathione to reduced glutathione (GSH) (in the presence of NADPH, which is oxidized to $\mathrm{NADPH}^{+}$). The plasma was added into cuvette one $\mathrm{cm}$ light path. Assay was carried out at $25^{\circ} \mathrm{C}$ and the absorbance is recorded at zero time, 1 and 5 minutes at $340 \mathrm{~nm}$. Then the decrease in absorbance per minute $(\Delta \mathrm{A} 340 \mathrm{~nm} /$ minute) was calculated through the following:

Glutathione Reductase Activity $(\mathrm{U} / \mathrm{L})=4019$ x $\Delta$ A $340 \mathrm{~nm} /$ minute

Plasma Lipid hydroperioxide level [21]: Thiobarbituric acid (TBA) reacts with MDA in acidic medium at temperature of $95^{\circ} \mathrm{C}$ for 30 minutes to form thiobarbituric acid reactive product. The reaction mixture was finally made up to $4.0 \mathrm{ml}$ with distilled water. Afterwards, samples were incubated for 1 hour in $95^{\circ} \mathrm{C}$. After being cooled with tap water, $1.0 \mathrm{ml}$ of distilled water and 5.0 $\mathrm{ml}$ of mixture of butanol-pryidine was added. The mixture was shaken for 10 minutes and then centrifuged at 4,000 rpm for 10 minutes. Butanol-pryidine layer was measured spectrophotometrically at $534 \mathrm{~nm}$.

Serum corticosterone level: Corticosterone concentrations were determined from serum using enzyme-linked immune sorbent assay (ELISA). Serum samples were collected into serum 
separator tubes. After clot formation, samples are centrifuged at $3000 \mathrm{rpm}$ for 10 minutes and serum was removed. Then it was diluted as 1:200 into Enzyme Immunoassay (EIA) diluent [22].

\section{Statistical Methods}

Data was coded and entered using the statistical package SPSS (Statistical Package for the Social Science) version 23. Then data was summarized using mean and standard deviation by one-way ANOVA (analysis of variance) to compare more than two groups as the regarded quantitative variable. In addition to use of the post hoc (LSD = least significant difference) test to find intergroups significance. A probability level of less than or equal 0.05 was considered statistically significant [23]

\section{RESULTS}

Effect of monosodium glutamate on behavioral tests, blood pressure and biochemical tests: The results showed significant anxiogenic behaviors induced by MSG. This was manifested by the significant decrease of the ambulation score (number of squares entered with all paws) and the frequency of rearing (standing on the hind limbs) of Group II during the open field test compared to that of Group I. (Table 1, Figure 2, 3). Moreover, in the successive alleys test, MSG-treated group spent significantly more time in alley (1) along with less time in alley (2) compared to the control group. (Table 1, Figures 4, 5). However, percentage change of SBP increased significantly (Table 1, Figures 6). Regarding biochemical tests, GR activity showed no difference, but MDA level and corticosterone level were increased significantly (Table 2, Figure $7,8,9)$.

\section{Effect of vitamin $C(100,200 \mathrm{mg} / \mathrm{kg})$, buspirone and their combination on behavioral tests:} Open field test (Table 1, Figure 2,3), Successive alleys test (Table 1, Figure 4,5): There was significant increase in the ambulation score in Group III compared to Groups I and II. Additionally, number of rearing was significantly increased compared to Group II. In the successive alleys test, Group III spent an insignificant amount of additional time in alley (2) compared to MSG-treated group along with less time in alley (1). These findings signify that low dose vitamin $\mathrm{C}$ has anxiolytic effect in the open field test although it has no anxiolytic effect in the successive alleys test. For example, Group IV resulted in significant anxiolytic effects in both tests, represented by a significant increase in both the ambulation score and frequency of rearing. Additionally, time spent in alley (1) was significantly decreased compared to both the control and MSG-treated group. Moreover, time spent in alley (2) was significantly increased compared to the control group, MSG-treated group, and all other treated groups.

In Group V, buspirone caused insignificant increase in the ambulation score and the number of rearings compared to MSG-treated group. However, in the successive alleys test, time spent in alley (2) was significantly increased compared to MSG-treated group, which indicates that it had less anxiolytic effect than vitamin $\mathrm{C}$, especially in high dose.

Combination of buspirone with vitamin C low dose and MSG in Group VI showed changes in the open field and the successive alleys tests that were similar to Group V. However, a combination of buspirone and vitamin C high dose and MSG in Group VII improved anxiety related behaviors significantly, compared to MSG-treated group and buspirone-treated group in both the open field and the successive alleys tests. 
3.3-Effect of vitamin $C(100,200 \mathrm{mg} / \mathrm{kg})$, buspirone and their combination on blood pressure (Table 1, Figure 6): \% change of SBP after behavioral tests Group III and IV improved significantly compared to the MSG group. This means that vitamin $\mathrm{C}$, in either low or high doses, caused improvement in percentage change of SBP. Furthermore, the combination of buspirone with vitamin $\mathrm{C}$, either with low dose or high dose, caused significant improvement in $\%$ change of SBP compared to MSG-treated group.

Effect of vitamin $\mathrm{C}(100,200 \mathrm{mg} / \mathrm{kg})$, buspirone and their combination on biochemical tests: Glutathione reductase (GR) activity (Table 2, Figure 7) Malondialdehyde (MDA) level (Table 2, Figure 8) Serum Corticosterone level (Table 2, Figure 9):

Low dose vitamin $\mathrm{C}$ demonstrated insignificant changes in the GR, MDA, and corticosterone levels compared to the MSG-treated group. However, high dose vitamin $\mathrm{C}$ showed significant improvement in the oxidative state parameters compared to MSG-treated group. This was represented by the increased level of GR and the decreased level of MDA. Furthermore, the corticosterone level was significantly decreased compared to the MSG-treated group. On the other hand, buspirone demonstrated a significant increase in the oxidative state along with a significant increase in plasma corticosterone level compared to the control and MSG-treated groups. However, a combination of buspirone with vitamin C, in either low doses or high doses, (Groups VI and VII) caused significant increase in the oxidative state (shown as decreased GR level and increased MDA level) and increased corticosterone level compared to Group I. However, there were insignificant changes in the biochemical tests results compared to Group II. Moreover, both groups demonstrated significant improvement in plasma corticosterone levels compared to (Group V).

Based on the present data it can be concluded that vitamin $\mathrm{C}$ has anxiolytic effect on MSGinduced anxiety in rats. However, the high dose $(200 \mathrm{mg} / \mathrm{kg})$ was more effective. Its anxiolytic effect is better than that of buspirone.

Table 1: Ambulation score and rearing frequency as parameters of Open Field test, Time spent in alleys (1) and (2) as parameters of Successive alleys test and \% change in SBP in the different groups

\begin{tabular}{|c|c|c|c|c|c|c|c|}
\hline & Control(I) & MSG(II) & $\begin{array}{l}\text { MSG + } \\
\text { VitC(L)(III) }\end{array}$ & $\begin{array}{l}\text { MSG + } \\
\text { VitC(H) } \\
(\text { IV) }\end{array}$ & $\begin{array}{c}\text { Buspirone + } \\
\operatorname{MSG}(V)\end{array}$ & $\begin{array}{l}\text { Buspirone } \\
+ \text { MSG + Vit } \\
\text { C(L)(VI) }\end{array}$ & $\begin{array}{l}\text { Buspirone } \\
+ \text { MSG + Vit } \\
\text { C(H)(VII) }\end{array}$ \\
\hline $\begin{array}{l}\text { Ambulation } \\
\text { score }\end{array}$ & $\begin{array}{l}16 \pm \\
1.79\end{array}$ & $2.83 \pm 1.17 *$ & $\begin{array}{c}26 \pm \\
8.63 * \# \%\end{array}$ & $\begin{array}{c}29.5 \pm \\
9.79 * \# \%\end{array}$ & $\begin{array}{l}10.67 \pm \\
3.61 \$ @\end{array}$ & $\begin{array}{c}10.5 \pm \\
4.37 \$ @\end{array}$ & $\begin{array}{c}14.33 \pm \\
2.88 \# \$ @\end{array}$ \\
\hline Rearing & $\begin{array}{l}10 \pm \\
0.89\end{array}$ & $2 \pm 0.89 *$ & $\begin{array}{l}11.33 \\
\pm 7.81 \#\end{array}$ & $\begin{array}{c}12.67 \pm \\
5.72 \# \%\end{array}$ & $4.67 \pm 2.73 @$ & $\begin{array}{c}5.33 \pm \\
3.14\end{array}$ & $\begin{array}{c}6.33 \pm \\
2.07\end{array}$ \\
\hline $\begin{array}{l}\text { Alley } 1 \\
\text { (seconds) }\end{array}$ & $\begin{array}{c}166.67 \pm \\
1.37\end{array}$ & $\begin{array}{l}172.5 \\
\pm 2.74^{*}\end{array}$ & $\begin{array}{c}164.67 \pm \\
9.85\end{array}$ & $\begin{array}{c}154 \pm \\
5.59 * \#\end{array}$ & $\begin{array}{c}164.33 \pm \\
4.8\end{array}$ & $\begin{array}{l}162 \pm \\
7.67\end{array}$ & $\begin{array}{l}158.5 \pm \\
12.36 \#\end{array}$ \\
\hline $\begin{array}{l}\text { Alley } 2 \\
\text { (seconds) }\end{array}$ & $\begin{array}{c}11.5 \pm \\
0.84\end{array}$ & $\begin{array}{c}2.5 \pm \\
0.55 *\end{array}$ & $\begin{array}{l}7.67 \pm \\
2.25^{*} @\end{array}$ & $\begin{array}{c}23.33 \pm \\
4.03^{* \# \$ \%}\end{array}$ & $\begin{array}{c}9.17 \pm \\
2.99 \# @\end{array}$ & $\begin{array}{c}12.67 \pm \\
1.37 \# \$ @\end{array}$ & $\begin{array}{c}19 \pm \\
13.24 \# \$ @\end{array}$ \\
\hline $\begin{array}{l}\text { \%change in } \\
\text { Blood } \\
\text { pressure } \\
(\mathrm{mm} \mathrm{Hg})\end{array}$ & $\begin{array}{c}9.31 \pm \\
6.45\end{array}$ & $\begin{array}{c}87.09 \pm \\
28.04 *\end{array}$ & $\begin{array}{l}18.54 \\
\pm 6.97 \#\end{array}$ & $\begin{array}{c}20.33 \pm \\
7.8 \#\end{array}$ & $7.50 \pm 13.70 \#$ & $\begin{array}{c}16.37 \pm \\
8.15 \#\end{array}$ & $\begin{array}{l}9.30 \pm \\
2.47 \#\end{array}$ \\
\hline
\end{tabular}


Table 2: Biochemical tests: GR, MDA and corticosterone levels in the different groups

\begin{tabular}{|c|c|c|c|c|c|c|c|}
\hline & Control (I) & MSG(II) & $\begin{array}{c}\text { MSG + Vit } \\
\text { C(L)(III) }\end{array}$ & $\begin{array}{l}\text { MSG + } \\
\text { Vit } \\
\text { C(H)(IV) }\end{array}$ & $\begin{array}{l}\text { Buspirone + } \\
\operatorname{MSG}(\mathbf{V})\end{array}$ & $\begin{array}{l}\text { Buspirone+M } \\
\quad \text { G } \\
+ \text { Vit C }(L)(V I)\end{array}$ & $\begin{array}{l}\text { Buspirone+MS } \\
\text { G } \\
+ \text { VitC(H)VII })\end{array}$ \\
\hline $\begin{array}{l}\text { Glutathione } \\
\text { reductase(GR) } \\
(\mathrm{U} / \mathrm{L})\end{array}$ & $\begin{array}{c}25.09 \pm \\
4.53\end{array}$ & $\begin{array}{c}20.07 \pm \\
8.98\end{array}$ & $\begin{array}{c}30.1 \pm \\
12.74 \%\end{array}$ & $\begin{array}{c}45.20 \pm \\
20.58 * \# \%\end{array}$ & $\begin{array}{c}1.17 \pm \\
0.58 * \# \$ @\end{array}$ & $\begin{array}{c}3.58 \pm \\
2.69 * \$ @\end{array}$ & $\begin{array}{c}620 \pm \\
3.37 \$ @\end{array}$ \\
\hline $\begin{array}{l}\text { MDA } \\
(\mathrm{nmol} / \mathrm{ml})\end{array}$ & $\begin{array}{l}5.69 \pm \\
1.27\end{array}$ & $\begin{array}{c}13.42 \pm \\
4.64 *\end{array}$ & $\begin{array}{l}7.65 \pm \\
1.36 \%\end{array}$ & $\begin{array}{r}4.62 \pm \\
0.65 \# \%\end{array}$ & $\begin{array}{l}16.37 \\
\pm 7 * \$ @\end{array}$ & $\begin{array}{c}15.30 \\
\pm 2.28 * \$ @\end{array}$ & $\begin{array}{l}11.85 \pm \\
3.7 @\end{array}$ \\
\hline $\begin{array}{l}\text { Corticosterone } \\
(\mathrm{ng} / \mathrm{ml})\end{array}$ & $\begin{array}{c}439.2 \pm \\
81.06\end{array}$ & $\begin{array}{c}1000.63 \pm \\
285.31 *\end{array}$ & $\begin{array}{c}647.4 \pm \\
207.58 \%\end{array}$ & $\begin{array}{c}220.97 \pm \\
105.78 \# \%\end{array}$ & $\begin{array}{c}2339.7 \pm \\
711.5 * \# \$ @\end{array}$ & $\begin{array}{c}1252.2 \pm \\
104.7 * \$ @ \%\end{array}$ & $\begin{array}{c}534.18 \pm \\
25.2 \%\end{array}$ \\
\hline
\end{tabular}

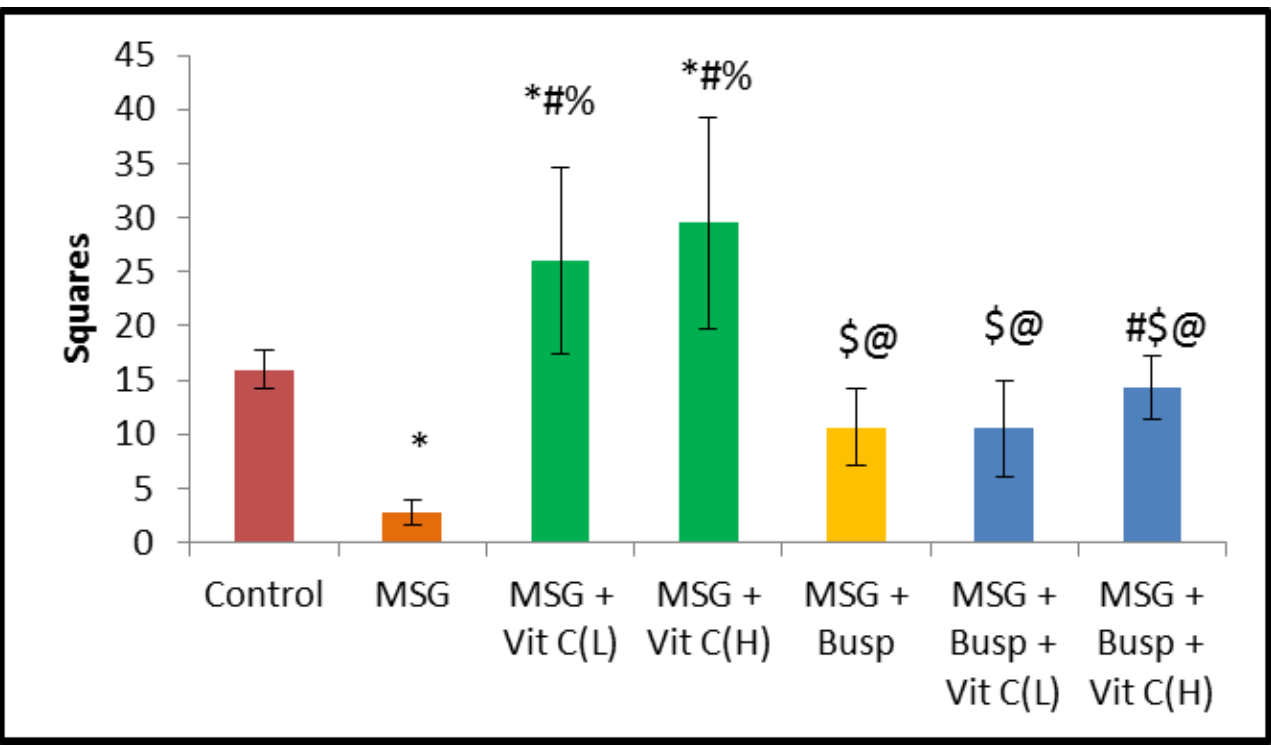

Figure 2. Ambulation score of the different groups

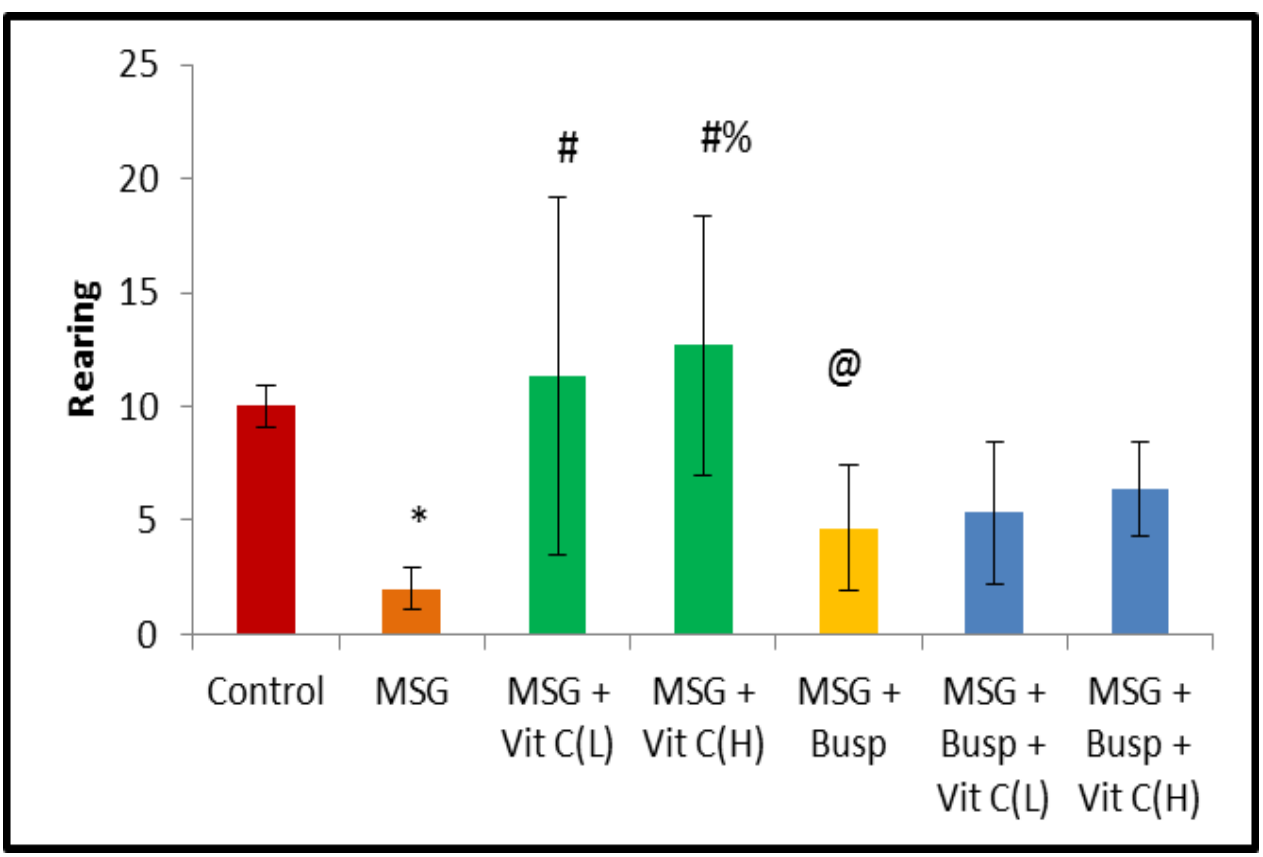

Figure 3. Rearing frequency of the different groups 


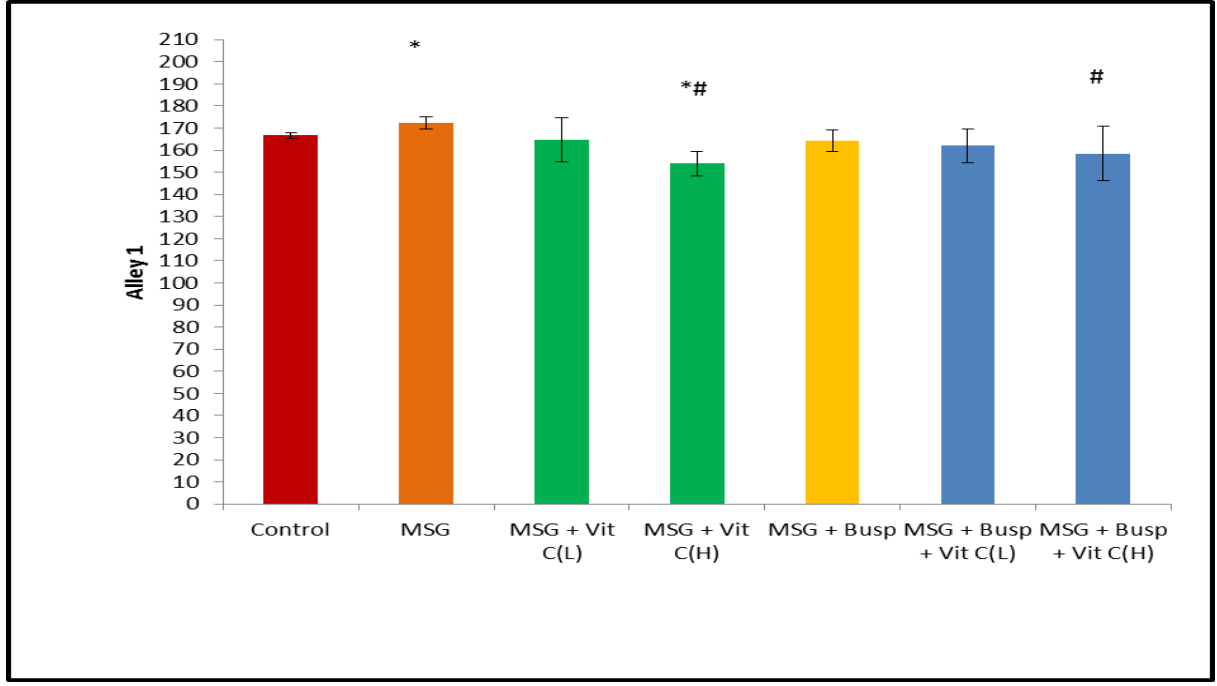

Figure 4. Time spent in Alley (1)

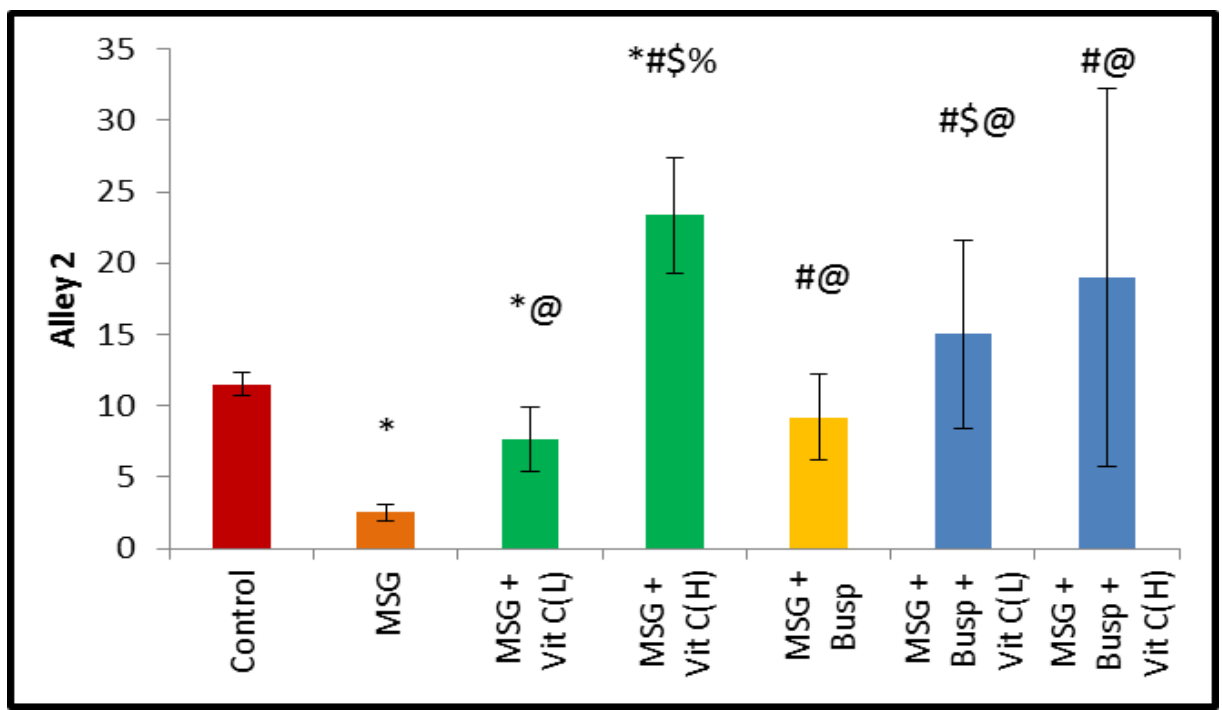

Figure 5. Time spent in Alley (2)

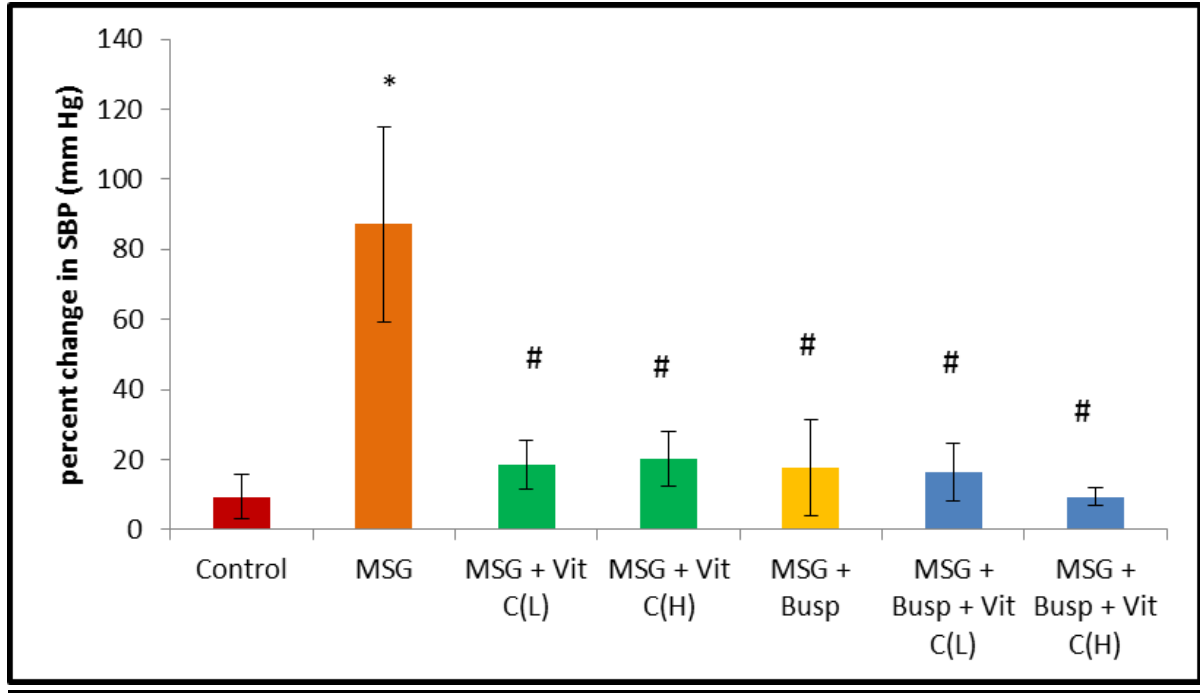

Figure 6. Percentage change in systolic blood pressure (measured before and after the tests 
Figure 2, 3: show the open field test (OFT) parameters that include total distance moved or ambulation score, rearing frequency respectively. Figure 4, 5: show sucessive alley test which calculates the amount of time spent in alley 1 , alley 2 respectively. The more time spent in alley (1) the higher anxiety, while Figure 6: show percentage change of SBP. The figures made based on the data in table 1. Each datum points indicate mean+SE. * $\mathrm{P}<0.05$ VS control group, \# $\mathrm{P}<0.05$ MSG group, \$ P<0.05 VS MSG + VitC (L) group, @ P $<0.05$ VS MSG + VitC $(\mathrm{H})$ group, \% P $<0.05$ VS MSG + Busp group

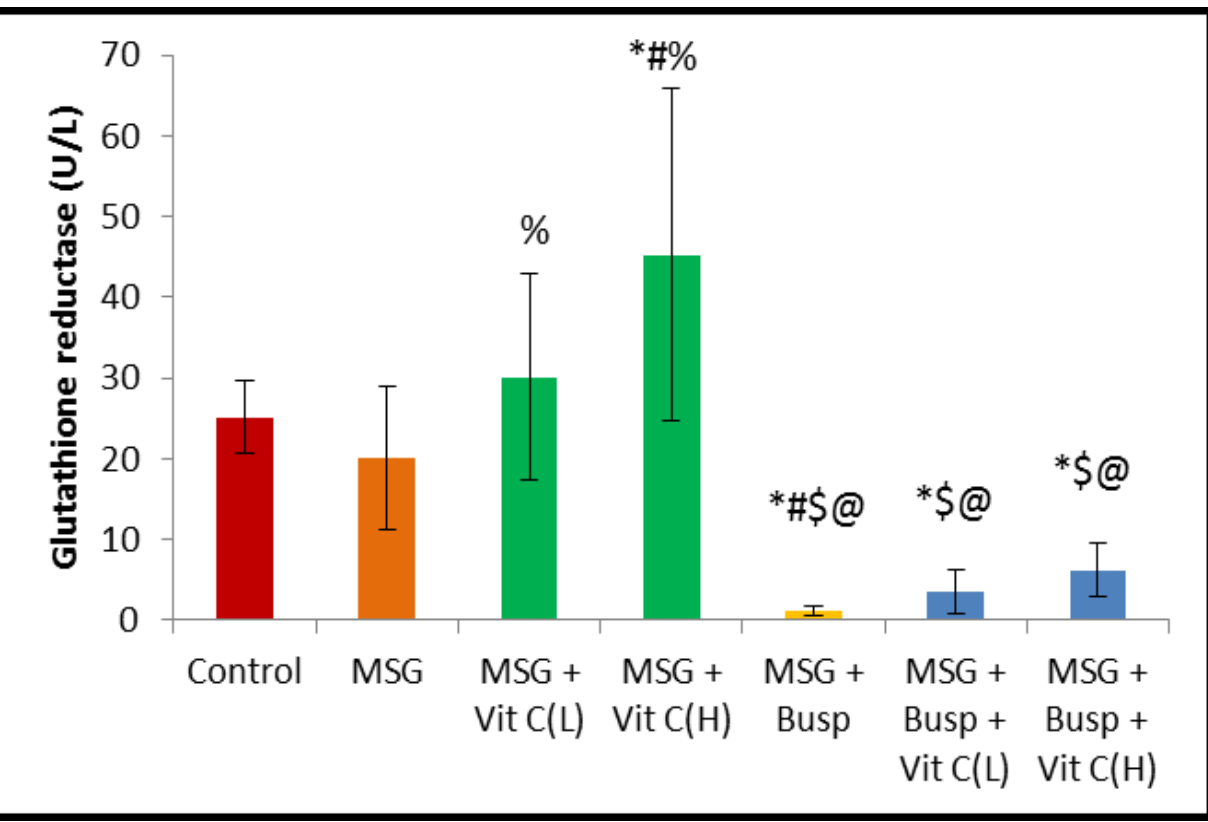

Figure 7. Glutathione reductase activity in the different groups

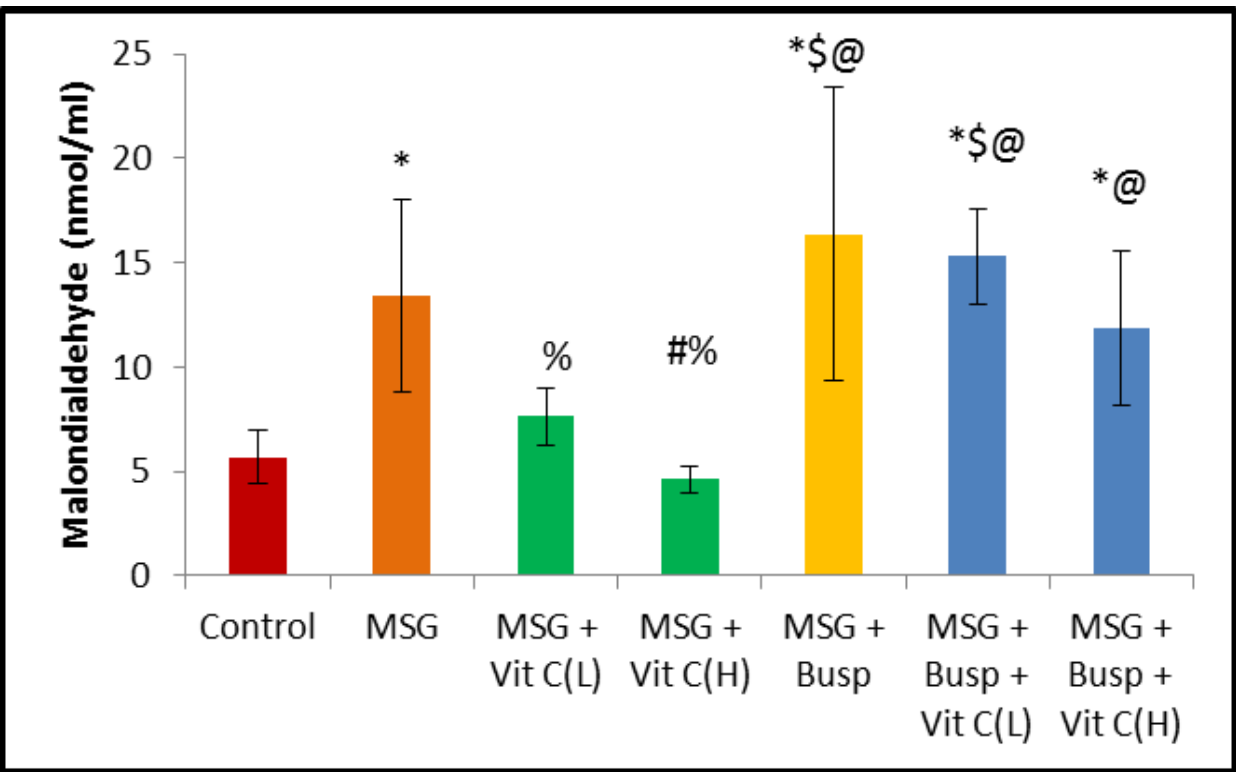

Figure 8. Malondialdehyde level in the different groups 


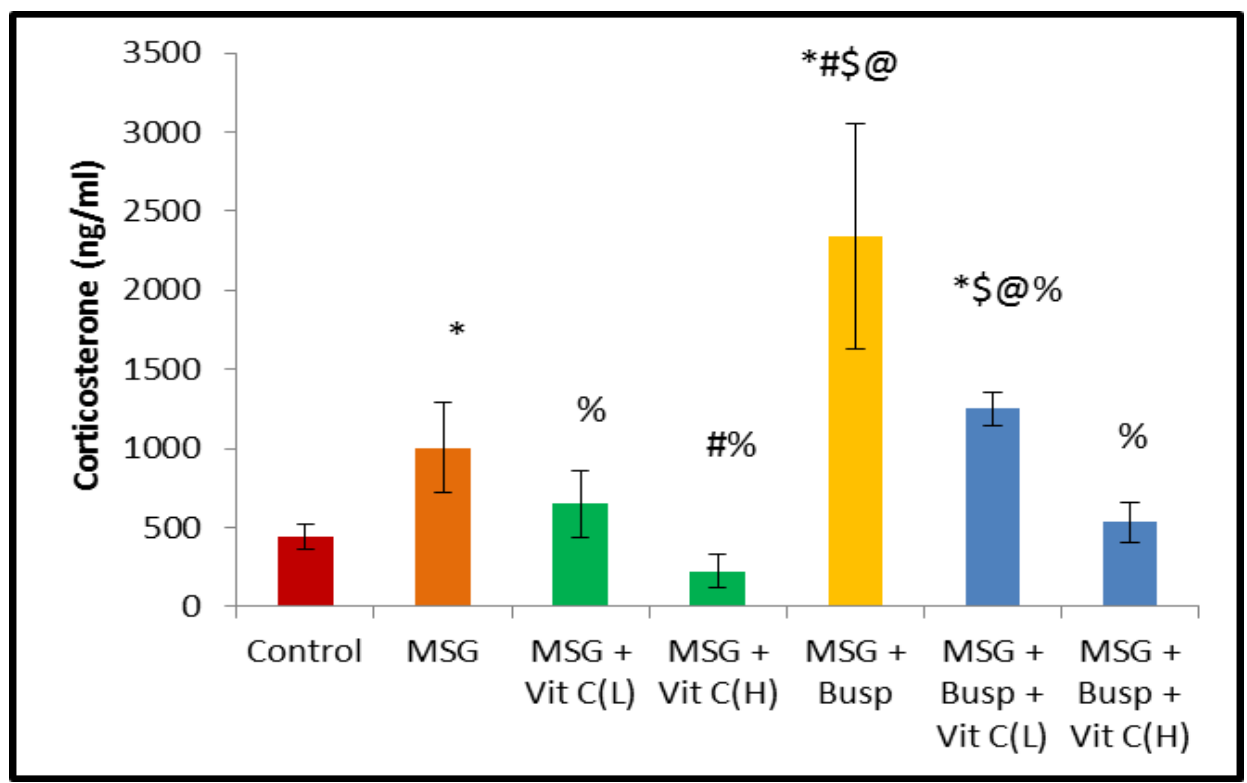

Figure 9. Serum corticosterone level in the different groups

Figure 7, 8, 9: show the biochemical parameters including measured plasma Glutathione reductase activity, plasma Malondialdehyde level and serum corticosterone level respectively. The figures made based on the data in table 2. Each datum points indicate mean+SE. * $\mathrm{P}<0.05$ VS control group, \# $\mathrm{P}<0.05 \mathrm{MSG}$ group, \$ $\mathrm{P}<0.05 \mathrm{VS} \mathrm{MSG}+\mathrm{VitC}$ (L) group, @ $\mathrm{P}<0.05 \mathrm{VS}$ $\mathrm{MSG}+\mathrm{VitC}(\mathrm{H})$ group, \% $\mathrm{P}<0.05 \mathrm{VS} \mathrm{MSG}+\mathrm{Busp}$ group

\section{DISCUSSION}

Buspirone is used for the treatment of anxiety disorders. However, it can take from one to three weeks to become clinically effective. This delayed onset of action is due to the time required to desensitize 5-HT $\mathrm{HT}_{1 \mathrm{~A}}$ presynaptic receptors [24]. In the present work, buspirone-treated group demonstrated neither insignificant decrease nor increase in the mean ambulation score and the mean number of rearing in the open field test compared to the control group or MSG-treated group respectively, while it caused significant increase in successive alleys test compared to MSG-treated group. A study mentioned that buspirone (at doses of 3 and $10 \mathrm{mg} / \mathrm{kg}$ ) did not reduce anxiety-like behavior in the open field test in the C $57 \mathrm{BL} / 6 \mathrm{~J}$ mice strain [25]. Moreover, it has been mentioned that buspirone could not affect anxiety during the open field test [26]. This was indicated by the decreased number of crossed squares compared to the control group.

However, vitamin $\mathrm{C}$ treated groups, especially in high doses, demonstrated significant improvement in the behavioral tests compared to the MSG-treated group. A combination of buspirone and vitamin $\mathrm{C}$ high dose improved anxiety related behaviors significantly compared to MSG-treated group and buspirone-treated group in both tests.

The anxiolytic effect of vitamin $C$ has been reported in the study of [27] who mentioned that vitamin $\mathrm{C}(160 \mathrm{mg} / \mathrm{kg})$ increased the walking frequency and the number of rearing in rats during the open field test. However, a study reported that vitamin C (at a dose of $200 \mathrm{mg} / \mathrm{kg}$ ) alone did not cause any significant changes in the locomotor activity of rats [28].

This was also in accordance to a study which mentioned that vitamin $\mathrm{C}(100 \mathrm{mg} / \mathrm{kg})$ significantly prevented the neurobehavioral changes in rats that were induced by MSG including 
anxiety in the elevated plus maze test [9]. This role may be due to the involvement of vitamin $\mathrm{C}$ in presynaptic reuptake of glutamate, which also inhibits binding of glutamate to the N-methyl D-Aspartate (NMDA) receptor [29]. Additionally, in another study vitamin C (250 mg/kg) decreased the glutamate levels and reversed the neuronal cell death induced by MSG in the hippocampus of rats [30].

Vitamin C or L-ascorbic acid, as an antioxidant, has been studied in many neuropsychiatric disorders [317]. It can improve cognition and memory. It also protects against Parkinson's disease and atherosclerosis of cerebral blood vessels. Moreover, vitamin C can decrease anxiety level which suggests potential function as an anxiolytic drug [32].

The underlying mechanism of this anxiolytic effect may be due to the antioxidant properties of vitamin $\mathrm{C}$. It can scavenge oxygen free radicals generated within the cells or plasma before they can damage DNA, proteins, or lipids [33]. Additionally, it promotes the ability of other antioxidants like vitamin $\mathrm{E}$ to break the chain of lipid peroxidation in the lipid bilayer of the cell membrane [34]. Moreover, another study discovered that vitamin $\mathrm{C}$ combined with vitamin $\mathrm{E}$ at a dose of vitamin E $400 \mathrm{IU}$ + vitamin C $1 \mathrm{~g} /$ daily for 14 weeks was effective in reducing the MDA level as a marker of lipid peroxidation in lead-exposed workers [35]. Additionally, the antioxidant enzymes activities including the GR enzyme were improved. This protective effect has been studied by Al-Harbil et al who reported that the treatment of the adult mice with vitamin $\mathrm{C}$ at a dose of $125 \mathrm{mg} / \mathrm{kg}$, prior to $\mathrm{MSG}$, restored the efficiency of the antioxidant enzymes [36]. Additionally, another study reported that vitamin $\mathrm{C}$ significantly increased the anxiolytic effect of progesterone through the reduction of the oxidative stress represented by low MDA levels. [37]. Another protective role of vitamin $\mathrm{C}$ against anxiety disorders relates to its function of the recycling of tetrahydrobiopterin, which is used in the conversion of L-tryptophan to 5-hydroxy-1-tryptophan in serotonin synthesis pathways [38].

Regarding clinical studies, a randomized, placebo-controlled trial revealed that a daily oral dose of $500 \mathrm{mg}$ of vitamin $\mathrm{C}$ had reduced anxiety levels in students [39].

In the all treated groups - vitamin $\mathrm{C}$ alone, buspirone by itself, or a combination of both there was significant decreased in the mean percentage change in SBP compared to MSG group. These findings are in agreement with a study which mentioned how vitamin $\mathrm{C}$ infusion $(3 \mathrm{~g}$ intravenously in $5 \mathrm{~min}$ ) significantly lowered the SBP in hypertensive patients. This action may be through an inhibitory effect on the sympathetic nervous system [40].

Additionally, another study reported that the administration of buspirone (at doses of 0.25 $\mathrm{mg} / \mathrm{kg}$ and $0.5 \mathrm{mg} / \mathrm{kg}$ ) reduced the SBP [41]. This may be due to increased parasympathetic activation and decreased activity of catecholamines and aldosterone.

In the present study, the plasma GR activity was insignificantly decreased in the MSGtreated group compared to the control group. However, the mean MDA activity was significantly increased. A study mentioned that MSG $(500 \mathrm{mg} / \mathrm{kg}$ ) increased the MDA and decreased the GSH concentrations in the brain of mice [42].

However, in the buspirone-treated group, the GR level was significantly decreased and MDA level was significantly increased compared to the control. These results refer to the possible role of buspirone in the increased oxidative stress state. Its combination with vitamin $\mathrm{C}$ (in either dose) could not protect against that oxidative stress. This is in contrast with another study that discovered buspirone caused antioxidant-like effects represented by reduced lipid peroxidation and restoration of the GSH level [43]. 
Regarding the serum corticosterone level, it was significantly increased in the MSG-treated group compared to the control group. This finding refers to the possible disturbing effect of MSG on the hypothalamic-pituitary-adrenal axis in rats.

This was supported by a study which mentioned how dysregulation of HPA axis function is another mechanism involved in MSG-induced anxiety [44]. MSG increases CNS glutamate level which in turn activates HPA axis, leading to increased glucocorticoids. These elevated glucocorticoids inhibit BDNF in the hippocampus and the prefrontal cortex, contributing to the development of depression and anxiety disorders [45]. Moreover, exposure to glucocorticoids contributes to the process of excitotoxicity, which occurs due to MSG. This harmful effect of glucocorticoids can be produced through the inhibition of the reuptake of glutamate from synapses [46]. In high doses, vitamin C significantly reduced the corticosterone level. This suggests the anti-hypercorticosteronism effect of vitamin $\mathrm{C}$, which may play a role in its protective effect against MSG-induced anxiety in rats.

In the buspirone-treated group, the mean corticosterone level was significantly increased compared to the control and MSG groups. This result refers to the possible role of buspirone in the activation of the HPA axis, which may explain its weak anxiolytic effect against MSGinduced anxiety and how it was also supported by [47] a study which demonstrated how the acute buspirone treatment (at a dose of $3 \mathrm{mg} / \mathrm{kg}$ ) induced anxiogenic behaviors in the open field test in albino Wistar rats. These behaviors were associated with the elevation of plasma corticosterone level compared to the baseline. Furthermore, the addition of vitamin $\mathrm{C}$ to buspirone in both doses improved the high corticosterone level compared to the buspironetreated group. These findings suggest the possible protective effect of vitamin $\mathrm{C}$ against high corticosterone level induced by buspirone. A study [48] reported how vitamin C supplementation (25 or $100 \mathrm{mg} / \mathrm{kg}$ ) decreased the corticosterone level in rats. Additionally, another study [49] reported that antioxidants such as vitamin $\mathrm{C}$ can protect against the oxidative damage induced by glucocorticoids.

The relationship between the increased corticosterone levels and anxiety disorders was explained by another study [50], which mentioned that glucocorticoid production contributes significantly to cellular ROS production due to the release of free electrons during the final step of cortisol synthesis. Additionally, another study [51] reported how the high level of glucocorticoids enhances oxidative phosphorylation. Although oxidative phosphorylation is vital to reform ATP, it is associated with the release of free electrons and ROS formation. These ROS affect the hippocampus, leading to its degeneration which is related to anxiety disorders, especially PTSD [52].

\section{CONCLUSION}

Vitamin $\mathrm{C}$ has an anxiolytic effect against MSG-induced anxiety which is more evident than buspirone, especially in the acute stage. Moreover, it can enhance the anxiolytic effect of buspirone when they are combined with each other. This effect is likely due to the antioxidant and the anti-corticosterone properties of vitamin. Further experimental studies are needed to find other mechanisms included in the potential anxiolytic effect of vitamin C.

Additionally, well-conducted clinical trials are needed to evaluate the usefulness of vitamin $\mathrm{C}$ to treat patients with anxiety symptoms, in addition to establishing the dose and supplementation times needed to reach positive results. Accordingly, we recommend using 
vitamin $\mathrm{C}$ as an anxiolytic drug, and to especially stress it being added to foods, especially for people suffering from anxiety, in addition to using vitamin $\mathrm{C}$ for any diseases that elevate corticosterone.

List of Abbreviations: Monosodium glutamate (MSG), Open Field Test (OFT), Systolic blood pressure (SBP), Malondialdehyde (MDA), Superoxide Dismutase (SOD), Glutathione Reductase (GR), Reduced Glutathione (GSH), Reactive Oxygen species (ROS), post-traumatic stress disorder (PTSD)

Competing Interests: All authors related to this study are members of the medical pharmacology department of Cairo University. They declare that there is no conflict of interest associated with this manuscript.

Authors' Contribution: Professor Dr. Aida Khattab conducted the study and revised every step; Mariam Habil cooperated in the practical work and helped write the manuscript.

Acknowledgments and Funding: This work was supported financially in part by the Cairo University and the biochemical results were conducted by the medical biochemistry department.

\section{REFERENCES}

1. Cryan JF, Sweeney FF: The age of anxiety: role of animal models of anxiolytic action in drug discovery. British journal of pharmacology 2011, 164(4):1129-61.

2. Noori S: An overview of oxidative stress and antioxidant defensive system. Open access scientific reports 2012, 1(8):1-9.

3. El HA: Lipid peroxidation end-products as a key of oxidative stress: Effect of antioxidant on their production and transfer of free radicals. InLipid peroxidation 2012. InTech.

4. Salim S: Oxidative stress and psychological disorders. Current neuropharmacology 2014, 12(2):140-7.

5. Ardayfio P, Kim KS: Anxiogenic-like effect of chronic corticosterone in the light-dark emergence task in mice. Behavioral neuroscience 2006, 120(2):249.

6. Conrad CD: Chronic stress-induced hippocampal vulnerability: the glucocorticoid vulnerability hypothesis. Reviews in the Neurosciences 2008, 19(6):395-412.

7. Pum ME, Huston JP, Muller CP: The role of cortical serotonin in anxiety and locomotor activity in Wistar rats. Behavioral neuroscience 2009, 123(2):449.

8. Maia TV, Cano-Colino $\mathrm{M}$ : The role of serotonin in orbitofrontal function and obsessive-compulsive disorder. Clinical Psychological Science 2015, 3(3):460-82.

9. Narayanan SN, Kumar RS, Paval J, Nayak S: Effect of ascorbic acid on the monosodium glutamate-induced neurobehavioral changes in periadolescent rats. Bratisl Lek Listy 2010, 111(5):247-52.

10. Hashem HE, Safwat ME, Algaidi S: The effect of monosodium glutamate on the cerebellar cortex of male albino rats and the protective role of vitamin $\mathrm{C}$ (histological and immunohistochemical study). Journal of molecular histology 2012, 43(2):179-86. 
11. Rai AR, Madhyastha S, Rao GM, Rai R, Sahu SS: A comparison of resveratrol and vitamin $\mathrm{C}$ therapy on expression of BDNF in stressed rat brain homogenate. IOSR Journal of Pharmacy 2013, 10:22-7.

12. Vaidya AH, Rosenthal DI, Lang W, Crooke JJ, Benjamin D, Ilyin SE, Reitz AB: Oral buspirone causes a shift in the dose-response curve between the elevated-plus maze and Vogel conflict tests in Long-Evans rats: Relation of brain levels of buspirone and I-PP to anxiolytic. Methods and findings in experimental and clinical pharmacology 2005, 27(4):245-56.

13. Archer J: Tests for emotionality in rats and mice: a review. Animal behaviour 1973, 21(2):205-35.

14. Díaz-Moran S, Estanislau C, Canete T, Blazquez G, Raez A, Tobena A, FernandezTeruel A: Relationships of open-field behaviour with anxiety in the elevated zero-maze test: focus on freezing and grooming. World Journal of Neuroscience 2014, 4(01):1.

15. Sestakova N, Puzserova A, Kluknavsky M, Bernatova I: Determination of motor activity and anxiety-related behaviour in rodents: methodological aspects and role of nitric oxide. Interdisciplinary toxicology 2013, 6(3):126-35.

16. Deacon RM: The successive alleys test of anxiety in mice and rats. Journal of visualized experiments: JoVE 2013, (76).

17. McHugh SB, Francis A, McAuley JD, Stewart AL, Baxter MG, Bannerman DM: Hippocampal acetylcholine depletion has no effect on anxiety, spatial novelty preference, or differential reward for low rates of responding (DRL) performance in rats. Behavioral neuroscience 2015, 129(4):491.

18. Bunag RD, Eferakeya JE: Reduced cardiovascular responsiveness to hypothalamic stimulation during urethane and amobarbital anesthesia. Pharmacology 1973, 10(3): 143-51.

19. Zoladz PR, Fleshner M, Diamond DM: Differential effectiveness of tianeptine, clonidine and amitriptyline in blocking traumatic memory expression, anxiety and hypertension in an animal model of PTSD. Progress in Neuro-Psychopharmacology and Biological Psychiatry 2013. 44:1-6.

20. Kraus A, Roth HP, Kirchgessner M: Supplementation with vitamin C, vitamin E or $\beta$ carotene influences osmotic fragility and oxidative damage of erythrocytes of zincdeficient rats. The Journal of nutrition 1997, 127(7):1290-6.

21. Ohkawa H, Ohishi N, Yagi K: Assay for lipid peroxides in animal tissues by thiobarbituric acid reaction. Analytical biochemistry 1979, 95(2):351-8.

22. Gong S, Miao YL, Jiao GZ, Sun MJ, Li H, Lin J, Luo MJ, et al.: Dynamics and correlation of serum cortisol and corticosterone under different physiological or stressful conditions in mice. PLoS One 2015, 10(2):e0117503.

23. Chan YH: Biostatistics 102: quantitative data-parametric \& non-parametric tests. blood pressure 2003, 140(24.08):79-00.

24. Olango WM, Finn DP: Affective and cognitive modulation of pain. InPain Therapeutics 2013: 269-308.

25. Thompson T, Grabowski-Boase L, Tarantino LM: Prototypical anxiolytics do not reduce anxiety-like behavior in the open field in C57BL/6J mice. Pharmacology Biochemistry and Behavior 2015, 133:7-17. 
26. Fomina MK, Avgustinovich DF, Tolstikova TG: Studies of the Effects of a Complex of Buspirone with Glycyrrhyzic Acid on the Behavior of Mice during Formation of an Anxious-Depressive State. Neuroscience and Behavioral Physiology 2016, 46(2):153-9.

27. Hughes RN, Hancock NJ, Thompson RM: Anxiolysis and recognition memory enhancement with long-term supplemental ascorbic acid (vitamin $\mathrm{C}$ ) in normal rats: possible dose dependency and sex differences; 2015.

28. Rezvani ME, Mirgalili A, Dashti-Rahmatabadi MH, Talebi AR: Effect of Glycyrrhiza Glabra and Vitamin C on Acrylamide-Induced Motor Dysfunction. SSU_Journals 2014, 22(5):1567-76.

29. Hansen SN, Tveden-Nyborg P, Lykkesfeldt J: Does vitamin C deficiency affect cognitive development and function? Nutrients 2014, 6(9):3818-46.

30. Shah SA, Yoon GH, Kim HO, Kim MO: Vitamin C neuroprotection against dosedependent glutamate-induced neurodegeneration in the postnatal brain. Neurochemical research 2015, 40(5):875-84.

31. Chambial S, Dwivedi S, Shukla KK, John PJ, Sharma P: Vitamin C in disease prevention and cure: an overview. Indian Journal of Clinical Biochemistry 2013, 28(4):314-28.

32. Pavlovic DM, Markisic MS, Pavlovic AM: Vitamin C In Neuropsychiatry. Serbian Journal of Experimental and Clinical Research 2015, 16(2):157-61.

33. Padayatty SJ, Katz A, Wang Y, Eck P, Kwon O, Lee JH, Chen S, et al.: Vitamin C as an antioxidant: evaluation of its role in disease prevention. Journal of the American college of Nutrition 2003, 22(1):18-35.

34. May JM: Vitamin C transport and its role in the central nervous system. InWater Soluble Vitamins. Springer Netherlands; 2012: 85-103

35. Rendon-Ramirez AL, Maldonado-Vega M, Quintanar-Escorza MA, Hernández G, Arevalo-Rivas BI, Zentella-Dehesa A, Calderon-Salinas JV: Effect of vitamin E and C supplementation on oxidative damage and total antioxidant capacity in lead-exposed workers. Environmental toxicology and pharmacolog 2014, 37(1):45-54.

36. Al-Harbi MS, El-Shenawy NS, Al-Weail NO: Effect of monosodium glutamate on oxidative damage in the male mice: modulatory role of vitamin C. Adv Food Sci 2014.

37. Ferdowsi K, Hatami H, Dehghan G: Investigation the protective effect of Vitamin C on anxiety and oxidative stress modulation in male rats treated with progesterone. Trakia Journal of Sciences 2016, 14(2):115.

38. Ward MS, Lamb J, May JM, Harrison FE: Behavioral and monoamine changes following severe vitamin C deficiency. Journal of neurochemistry 2013, 124(3):363-75.

39. Ribeiro CU: Effects of oral vitamin C supplementation on anxiety in students: a doubleblind, randomized, placebo-controlled trial. Pakistan Journal of Biological Sciences 2015, 18(1):11-8.

40. Bruno RM, Daghini E, Ghiadoni L, Sudano I, Rugani I, Varanini M, Passino C, et al.: Effect of acute administration of vitamin $\mathrm{C}$ on muscle sympathetic activity, cardiac sympathovagal balance, and baroreflex sensitivity in hypertensive patients. The American journal of clinical nutrition 2012, 96(2):302-8. 
41. Farooq RE, Haleem DJ, Haleem MA: Dose related effects of buspirone on serum electrolyte balance, plasma osmolality and systolic blood pressure (SBP) in rats. Pak J Pharm Sc 2007, 20:295-9.

42. Umukoro S, Oluwole GO, Olamijowon HE, Omogbiya AI, Eduviere AT: Effect of monosodium glutamate on behavioral phenotypes, biomarkers of oxidative stress in brain tissues and liver enzymes in mice. World Journal of Neuroscience 2015, $5(05): 339$.

43. Kumar A, Kaur G, Rinwa P: Buspirone along with melatonin attenuates oxidative damage and anxiety-like behavior in a mouse model of immobilization stress. Chinese journal of natural medicines 2014, 12(8):582-9.

44. Evanson NK, Herman JP: Role of paraventricular nucleus glutamate signaling in regulation of hpa axis stress responses. Interdisciplinary information sciences 2015, 21(3):253-60.

45. Judd LL, Schettler PJ, Brown ES, Wolkowitz OM, Sternberg EM, Bender BG, Bulloch $\mathrm{K}$, et al.: Adverse consequences of glucocorticoid medication: psychological, cognitive, and behavioral effects. American Journal of Psychiatry 2014, 171(10):1045-51.

46. Sorrells SF, Munhoz CD, Manley NC, Yen S, Sapolsky RM: Glucocorticoids increase excitotoxic injury and inflammation in the hippocampus of adult male rats. Neuroendocrinology 2014, 100(2-3):129-40.

47. Hestermann D, Temel Y, Blokland A, Lim LW: Acute serotonergic treatment changes the relation between anxiety and HPA-axis functioning and periaqueductal gray activation. Behavioural brain research 2014, 73:155-65.

48. Choi JY, dela Pena IC, Yoon SY, Woo TS, Choi YJ, Shin CY, Ryu JH, et al.: Is the anti-stress effect of vitamin $\mathrm{C}$ related to adrenal gland function in rat? Food Science and Biotechnology 2011, 20(2):429-35.

49. Niu Y, Herrera EA, Evans RD, Giussani DA: Antioxidant treatment improves neonatal survival and prevents impaired cardiac function at adulthood following neonatal glucocorticoid therapy. The Journal of physiology 2013, 91(20):5083-93.

50. Crespi EJ, Williams TD, Jessop TS, Delehanty B: Life history and the ecology of stress: how do glucocorticoid hormones influence life-history variation in animals? Functional Ecology 2013, 27(1):93-106.

51. Spiers JG, Chen HJ, Sernia C, Lavidis NA: Activation of the hypothalamic-pituitaryadrenal stress axis induces cellular oxidative stress. Frontiers in neuroscience 2015, 8:456.

52. Miller MW, Sadeh N: Traumatic stress, oxidative stress and post-traumatic stress disorder: neurodegeneration and the accelerated-aging hypothesis. Molecular psychiatry 2014, 19(11):1156-62. 